\title{
The Augmented Selfie
}

\author{
Carla Gannis \\ Pratt Institute \\ Department of Digital Arts \\ Brooklyn, NY, USA \\ cgannis@pratt.edu
}

\begin{abstract}
In 1901 L. Frank Baum, the author of The Wonderful Wizard of Oz, imagined a kind of augmented reality (AR), viewed through spectacles, that could indicate specific characteristics about a person invisible to the naked eye. Today, AR allows artists to place virtual elements: videos, 3D graphics and audio, into the physical world, providing "mixed reality" experiences that can offer new perspectives on identity and subjecthood in the twenty-first century. This paper will highlight how I have implemented selfie vernacular and augmented reality technologies as storytelling devices in identity construction. The drawings and expanded AR narratives in The Selfie Drawings, a mixed reality artist's book, are an inventory of how a self, both the physical and virtual body, can be perceived in the Digital Age. Using 2D and 3D elements in my work, fragmenting the body, attaching it to, or intertwining it with digital augmentation devices, I am pondering the state of existing simultaneously IRL and URL in symbiotic relationships with technology and mediated culture.
\end{abstract}

Digital storytelling. Augmented reality. Mixed reality. Selfies. Augmented selfies. Artist's books.

\section{ORIGINS}

Since 2015 I have been taking a digital inventory, through The Selfie Drawings project, of how a self, both the physical and virtual body, can be projected and perceived in the Digital Age. The project has traversed several digital media methodologies - from digital drawing to $4 \mathrm{~K}$ video, to an augmented reality (AR) artist book, (winner of the 2016 Lumen Prize Founder's Award).

My artist book transcends the parameters of the traditional static page through the dynamic virtual experiences that I have released serially over the course of a year. Followers of the project have returned to The Selfie Drawings book on a weekly basis to find and activate expanded narratives and new iterations of "self" through the screens of their smart devices.

Incorporating photographic 2D and postphotographic 3D elements into my works, I present "selfiehood" through a prismatic avatar who has simultaneous IRL and URL agency. I, she, they and we are all involved in symbiotic relationships with technology.

The internet appears to us as a virtual, dematerialised space where we have greater access to the collective conscious than ever before, but "to be" we still must negotiate our conscious bodies and our palpable hardware in a physical realm. Through AR we are able to experience poetic visual instantiations of how evanescence and permanence, the material and non-material can overlap.

By discussing the themes and technologies that give definition to The Selfie Drawings, this paper will reflect on the heightened experiences that can occur when physical markers cohabitate with digital domains, when "real" selves interplay with virtual ones. It's no longer either <> or; real world or "Second Life;" metaverse or meatspace. It is all LIFE now, and artists have always been very successful at reflecting on and teasing out the intriguing parts of life. 


\section{A BRIEF HISTORY OF AR}

As early as the dawning of the twentieth century, visionaries have been imagining devices that could overlay virtual images and text onto the physical world. For instance, $L$. Frank Baum, imagined in his book The Master Key: An Electrical Fairy Tale, Founded Upon the Mysteries of Electricity and the Optimism of Its Devotees (1901) a kind of augmented reality, viewed through spectacles, that could indicate specific characteristics about a person invisible to the naked eye (Carmichael 2016). Baum's version of AR communicates rather didactically and somewhat ominously. Evil people bare the virtual letter $\mathrm{E}$ on their foreheads, and the foolish are represented by $\mathrm{F}$, etc. Nonetheless, it is remarkable, 115 years before the game Pokemon GO (http://www.pokemon.com/us/pokemon-videogames/pokemon-go/) popularized AR or the British television series Black Mirror (http://www.theverge.com/2016/10/25/134010 20/black-mirror-season-3-episode-2-playtestrecap) gave us pause regarding AR's future implications, storytellers were speculating on the possibilities of expanding our sensory perceptions via augmentative devices.

In 1968, Ivan Sutherland built the "Sword of Damocles," a head-mounted device that superimposed a geometric grid over the user's view of a room. It was a cumbersome contraption that lived up to its nickname, as it hung portentously over the head of its user. Sutherland is considered the founder of AR and Virtual Reality (VR), (Hollerer \& Schmalstieg 2016a) as well as being an Internet pioneer.

Since the 1990s, AR has been deployed in fields as diverse as art, medicine (Hollerer \& Schmalstieg 2016b) and US football (Pollock 2017). For over two decades, artists have been deploying $A R$, in the words of Professor Rewa Wright, as a "reconfiguration of traditional perceptions of interface, audience participation, and perceptual experience" (Wright 2015a). These artists, many of whom are engineers and programmers as well, subvert the commercial or industrial uses of the medium (Wright 2015b).

Artist Will Pappenheimer (2013), an early practitioner of geo-locative $A R$, is insightful in his perceptions on augmentation:
"Reality is always already augmented. Consider for example, that every experience is augmented by memory, by identity or by imagination. A site on a mountainside is potent with stories, the collective grid of human mapping, or the possible presence of gods. In other words, any investigation of how we perceive or represent 'reality' reveals the many ways in which we personally and socially augment the world around us, with or without media. As artists, our interest is often to shift these augmentations or to provide new ones."

My own preoccupations with augmented reality and virtual holography began at age seven, upon seeing Star Wars. Princess Leia appearing to Obi-Wan Kenobi as a holographic message thrilled me. I dressed up as Leia for Halloween that year, and first began dreaming of how I would broadcast my own virtual projections one day.

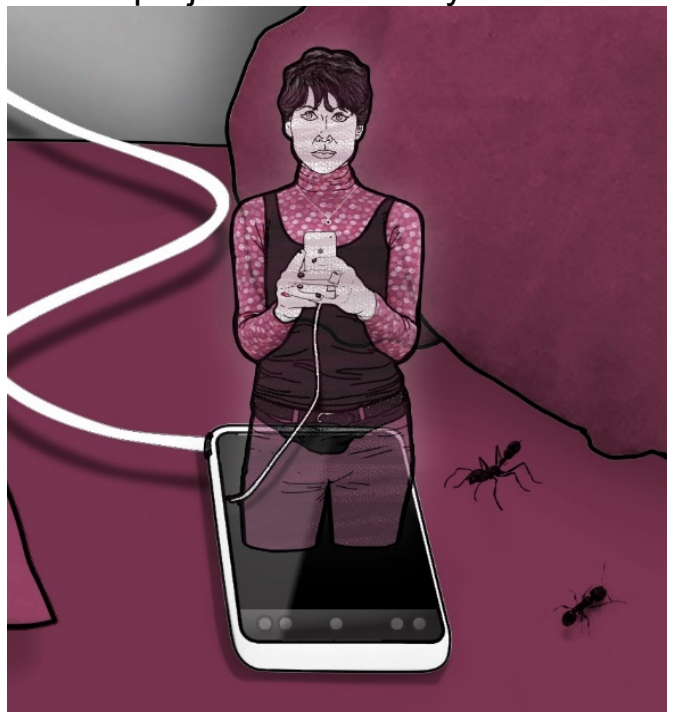

Figure 1: detail of Selfie Drawing 20 "Leia," (February 2015)

\section{THE SELFIE IN SELF-PORTRAITURE}

Self-portraiture has a long lineage, and I imagine the first self-portrait would be difficult, if not impossible to trace. Apparently an Australian named Hopey first coined the term "selfie" in 2002. By 2013 the young upstart selfie had properly entered the modern English lexicon by its inclusion in the OED (Kruszelnickia 2014). Smartphones with frontfacing cameras and apps like Instagram and Snapchat have become agents for representing millions of "selves" as willingly mediated subjects. I will also note here that with its AR filters, Snapchat is leading the way in augmented selfie photography. 


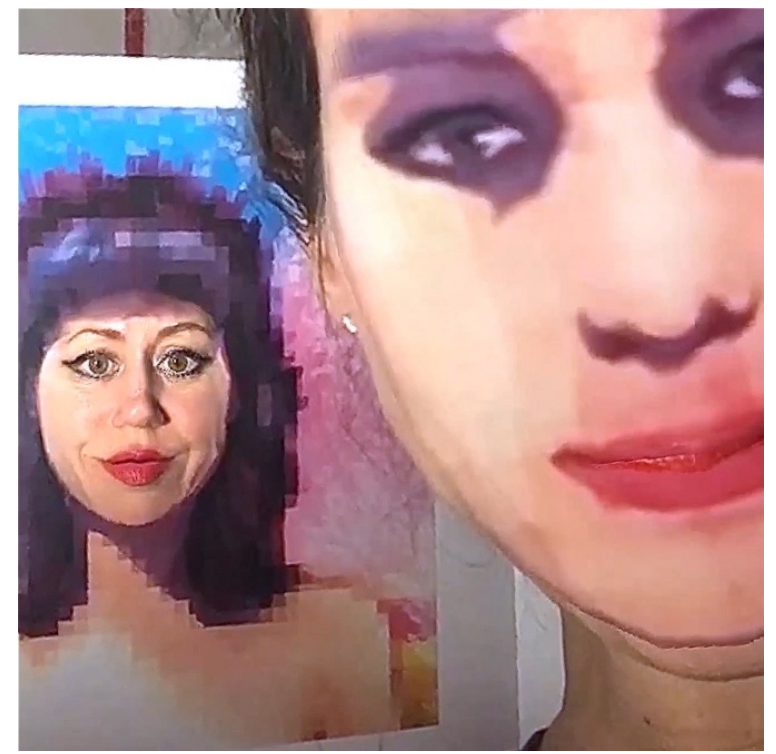

Figure 2: AR Blipp 4 (March 2016) of Selfie Drawing 32 "Self Portrait" (May 2015) *produced using the Snapchat swap face filter

A self-portrait, whether a painting or a photograph, has traditionally been associated with the arts, coming out of a creative impulse to explore the self through an aesthetic visual language. Selfies are more situated in networked communication. They are a kind of online performance, where we act out our lives through a device and are in control of framing how we want to be perceived. They also are produced at a much faster frequency and shared more instantaneously than selfportraits, which begs the question, is it a selfie if it is not uploaded to a network?

In her Medium essay "Selfie: The revolutionary potential of your own face, in seven chapters" writer Rachel Syme begins with Shot One of a woman snapping "a picture of herself, by herself" (2015a). The woman takes numerous selfies and then adjusts them with filters and lighting techniques until deciding on "the September issue of her face" (2015b) that she intends to share on Instagram. Syme then describes the separation between the self and the selfie that occurs once the image is uploaded:

\footnotetext{
"She pushes send and it's done. Her selfie is off to have adventures without her, to meet the gazes of strangers she will never know. She feels excited, maybe a little nervous. She has declared, in just a few clicks, that she deserves, in that moment, to be seen. The whole process takes less than five minutes."
}

\subsection{A Selfie Culturally-Defined}

I drew my first self-portrait in 1978, at 8 years old. I was reading Jane Eyre at the time, and I was a big fan of Wonder Woman. I looked in the mirror and began to draw my reflection. By the time I finished the drawing, I had made myself into a composite of a Victorian woman with a star-studded tiara and bulletproof cuffs. Throughout the 1980s and 90s I painted, photographed and video-recorded myself, as part of an artistic practice that involved role playing as much as self portraiture.

In 2006, I began to join social media sites, and it was then that I posted my first "legitimate" selfie; one that was digitally enhanced and alluding to the Mona Lisa's mysterious demeanour, but a selfie all the same. This was quite a different experience. I was not sharing a photo or drawing with a close friend; nor in a classroom for a critique; nor in a gallery exhibiting an objet d'art. I was disseminating "myself" to multitudes of people, inside and outside of my personal networks, as a new mode of communication.

In looking at the prevalence of self-images "clouding" the Internet today, it can be easy to assume we are a culture obsessed with the reflections provided to us by expedient camera and Wi-Fi technologies.

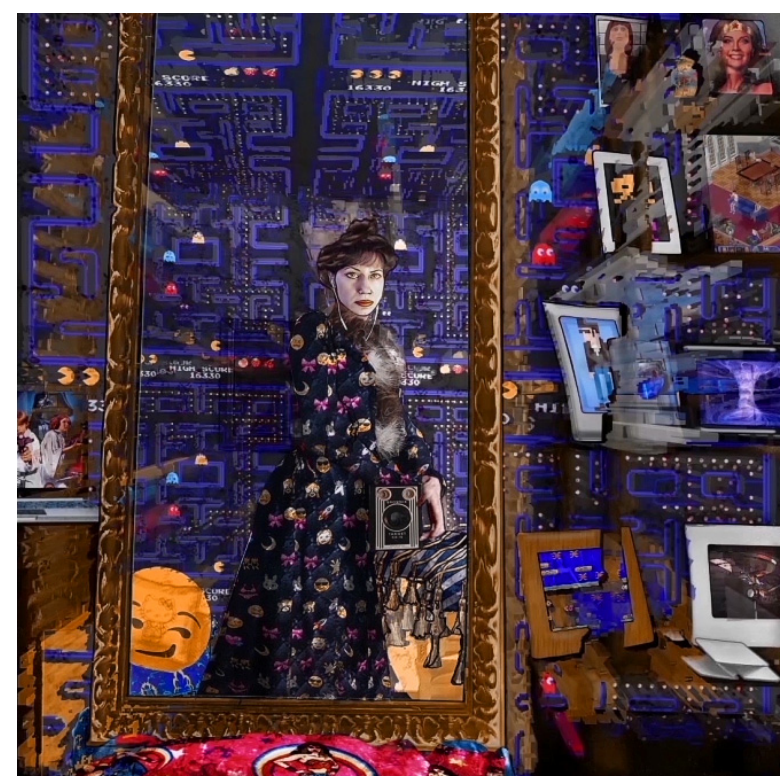

Figure 3: AR Blipp 11 (May 2016) of Selfie Drawing 46 "Zelig," (September 2015)

However, there could be other cultural forces that underlie our need to imprint our faces on 
the digital walls that very well may outlast us, for instance the threat of anthropogenic climate change that could eradicate our "collective human face" from the planet. Or an ever-increasing global population that makes it more difficult to concentrate on the affect of any single human life. Even the spectre of artificial intelligence superseding the human race, once a seemingly far-fetched premise, has begun to spook prominent scientists and philosophers.

To back track to Syme's Shot One, is the selfie-taker in her essay consciously asserting her identity as a response to the extreme situations I have described above? I doubt it. More likely, as Syme suggests, she is interested in controlling her own narrative and feeling comfortable with declaring herself as a variable in twenty-first century codes of representation.

Yet, on a subconscious level I would argue these underlying threats to humanity as we "know it," permeate through culture and affect how we, as humans, lay claim to our lives, our identities, and our desires to imprint something of ourselves on the walls and pages of communication networks.

Over 40,000 years ago our ancestors felt a necessity to imprint their hands-on cave walls with the technologies afforded to them via natural compounds. Today we encode our identities by harnessing synthetic technologies. These encryptions may one day carry the last residue of what it was like to be human in the twenty-first century.

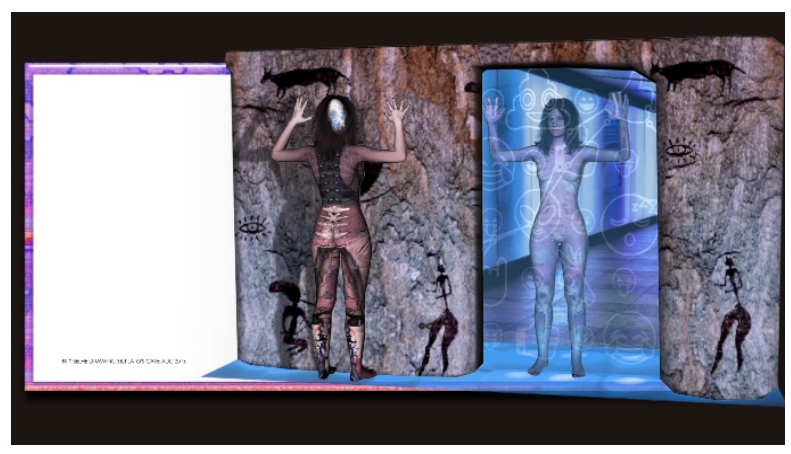

Figure 4: AR Blipp 45 (Jan 2017) of Selfie Drawing 38 "Plato's Cave" (August 2015)

\section{SELFIE DRAWINGS}

Over the course of a year I photographed myself often, with my iPhone, iPad, or my laptop camera, then, instead of posting an image immediately I would digitally draw over the photograph.

As I worked on these drawings, I added elements to the image to build an "out of the ordinary" narrative from a photo taken in a very quotidian space: my bedroom, or studio, or office. Through this process, I tried to resist the impulse to share a representation of myself, simply as myself, before I had the chance to clarify what that iteration of "me" could suggest in a broader social context.

I worked sometimes for days on one piece, to draw out content that addressed things like branded identity, age and body estimation, surveillance culture, and agency online. After I finished each drawing, to complete the cycle of contemporary selfie-portraiture as identity performance, I upload it to several social media platforms. In slowing down the process of taking and making a selfie, I hybridised selfies with self-portraiture.

Other than committing to making fifty-two selfie drawings over the course of a year, I did not set restrictions on my drawing process. As I continued, and became more comfortable with both revealing and subverting the "self," the works became more multi-dimensional. I already was in the process of learning Blippar AR technologies (https://blippar.com/en/), but at this phase, producing a static image, and sharing it weekly, was the focus of my storytelling.

\subsection{Transcriptions and Mashups}

Many of my projects begin with a drawing phase. Over time, as the concept begins to crescendo in my head, I develop themes and variations of the original drawings, transcribing them for more dynamic media platforms. Realising that the drawings would ultimately evolve into $4 \mathrm{~K}$ video and layered $A R$ experiences, collage became a more central component in developing them, and in the expression of the multitudinous identities that were now exploding from my consciousness on a weekly basis. 


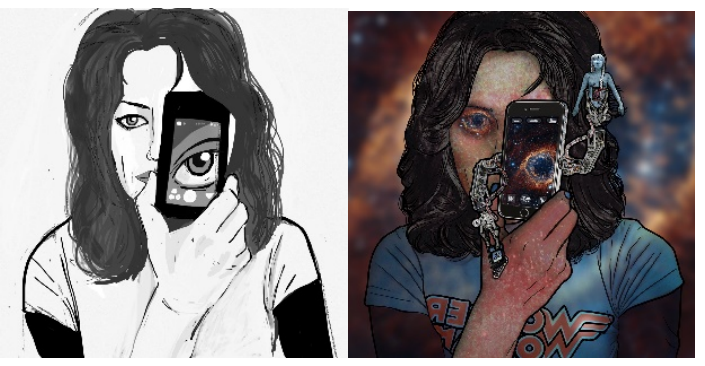

Figure 5: The 1st Selfie Drawing (January 2015) and the Last Selfie Drawing "Powers of Ten" (January 2016)

These works are as much role-playing mashups as self-confessional testaments: a middle-aged "cougar" in her bedroom trying to channel Wonder Woman and Shiva; a female immersed in a Google Deep Dream environment - facing the implications of posthumanism wrought by Artificial Intelligence $3 \mathrm{D}$ prints her body as a replacement for the physical one; or a replicating "Nude Descending a Staircase." Unlike Marcel Duchamp's nude, this woman descends from a spaceship, selfie recording device in hand, and enters a flooded, stormy environment seemingly on the brink of disaster.

\subsection{A Oneness with Everything}

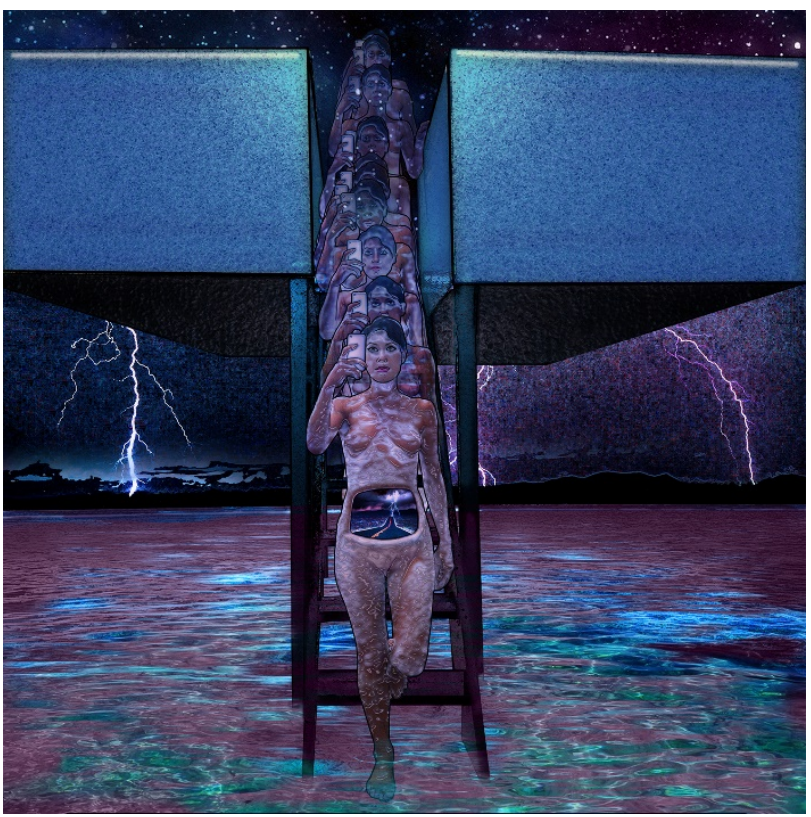

Figure 6: Selfie Drawing 37 "Nude Descending a Staircase" (July 2015)

Dorothy R. Santos (2016) in her essay "A Oneness with Everything," written as the catalogue essay for The Selfie Drawings book, eloquently describes the digital-age storytelling I am attempting:
"The 52 selfie drawings create reflective stories that can be told and re-told with something new to discover with every single viewing. We are not only looking at the artist looking at herself, we are seeing her surroundings and visual cues that let us know what she is perceiving and contemplating in a long, extended moment. This rich, robust, and non-linear work begs to be seen through the multi-faceted lens of technology and historical references that lead us to a further proof of a self."

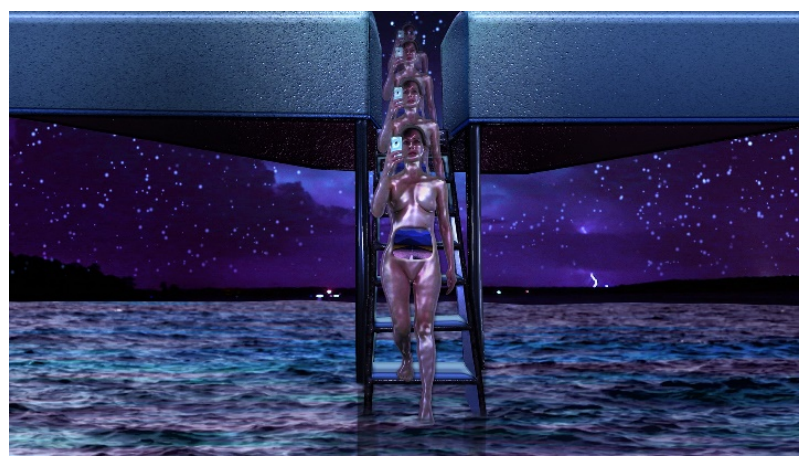

Figure 7: "Nude Descending a Staircase" 4K Video Still (January 2016)

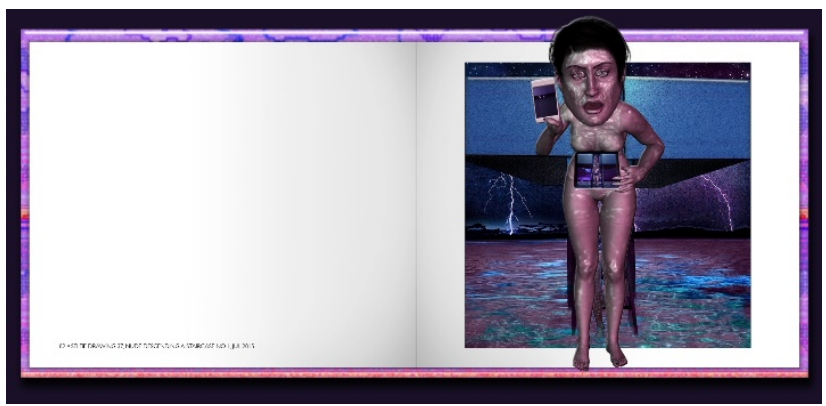

Figure 8: AR Blipp 40 (January 2017) of Selfie Drawing 37 "Nude Descending a Staircase" (July 2015)

\section{AUGMENTED SELFIES}

In January 2016, I finished the drawing portion of the project. Concurrently I produced seventeen $4 \mathrm{~K}$ moving image transcriptions of selected drawings for an exhibition entitled "A Subject Self-Defined."

(http://transfergallery.com/a-subject-selfdefined-carla-gannis/). In March of the same year, I published the selfie drawings as a book, and began to augment one drawing a week for the next fifty-two weeks. My adventures in mixed-reality had begun, as I embarked on producing a twenty-first century pop-up book, serialised like a graphic novel, in the non-linear format of an e-lit (electronic literature) website. Hybridity is the hallmark of my artistic practice. 
There are key differences between static or moving images locked to the rectangle of a two-dimensional page or screen, and the three-dimensional augments that can perceptually explode out of these bounds.

In the drawings and videos I'm grappling with and ultimately describing a state of existing in virtual and physical domains simultaneously; however in the augments I am providing a platform where one can actually experience this simultaneity.

\subsection{Acting in the Gaps Between}

A Robert Rauschenberg quote has stuck with me since my college days, when I studied traditional oil painting and printmaking. "Painting relates to both art and life. Neither can be made. I try to act in the gap between the two" (Rauschenberg 1959).

Since transitioning from pigments and canvas to pixels and screens, I have often described my own practice as acting between the gap of virtual and real. With AR however, that gap is closing.

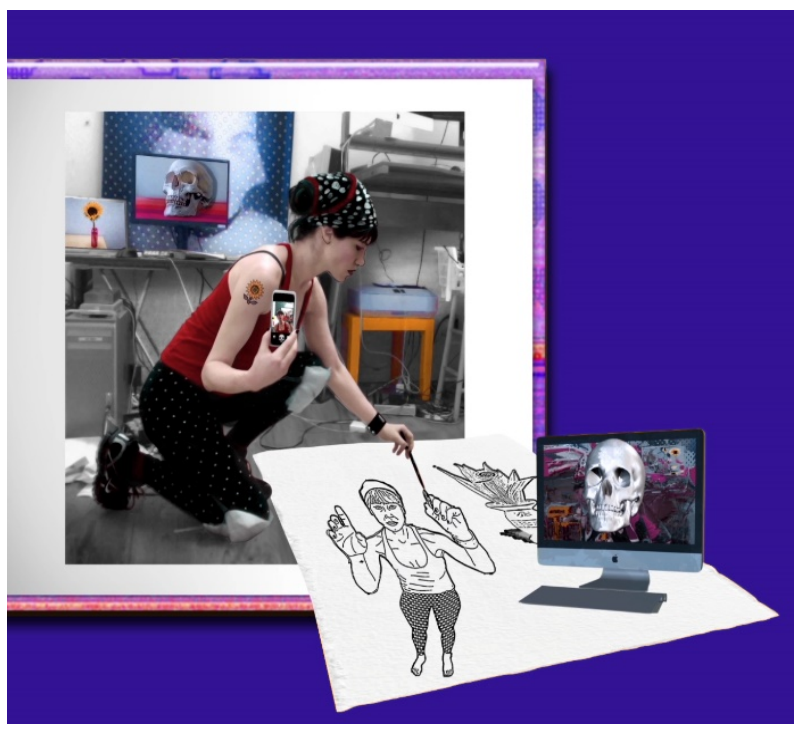

Figure 9: AR Blipp 25 (August 2016) of Selfie Drawing 23 "Skulls, Flowers and Dots" (March 2015)

\subsection{Interfacing}

Author and scholar Natasha Chuck (2016) recently wrote an essay on The Selfie Drawings project entitled "Self-made: Constructing identity at the threshold between virtual and physical realms." I am including quotes from the section of her essay entitled
"Beyond The Screen," in which she elucidates on the nature of the augmented interactive experience:

\begin{abstract}
"A number of Gannis's self-portraits employ the use of augmentation to transcend the physical barriers of the digital (or printed) frame, and embark on new perceptual understandings and interactions. In addition to dynamic screens and large-scale projections, the use of augmented reality (AR) brings to life, so to speak, a selection of portraits, and contributes to the frame-within-a-frame motif established in other works. After installing the free Blippar application (available to iOS, Android and Windows devices) users can aim their smart phones towards the selected images to activate their digital content. Blippar combines image recognition and data overlaying technologies to complete the realtime effects embedded in Gannis's AR images. Like the conversational nature of selfies, augmented realities encourage audiences to think relationally, rather than exclusively aesthetically or visually."

"Audiences negotiate the use of the display mechanism - the smartphone or other deviceas well as the physical environment in which the experience is taking place, in addition to the virtual content itself and its relations to those external environments. This unique combination contributes to a sense of intimacy with the selfportraits. The select Selfie Drawings emerge from the confines of the frame and immobility and strengthen the possibility of social connection. However, on their own, they function less like conversation starters and more like personal statements or short digital performances."
\end{abstract}

\section{FOUR SEASONS}

A panoply of topics has preoccupied me while developing this project. I have broken it down into Four Seasons, beginning with "Plato's Cave" as Season One, the season of atavism, myth, semiotics and past/future collisions. "The Eccentric" represents Season Two where Cosplay collides with artistic and literary tropes. "Bunny" begins Season Three, a time of comedic eroticism, extroverted-interiority and playful remixes of the Canon. Season Four begins with "Nude Descending a Staircase." It is the season of pop-future disaster aesthetics mixed with cultural and environmental collapse, and post-human potentialities. 


\subsection{Season One}

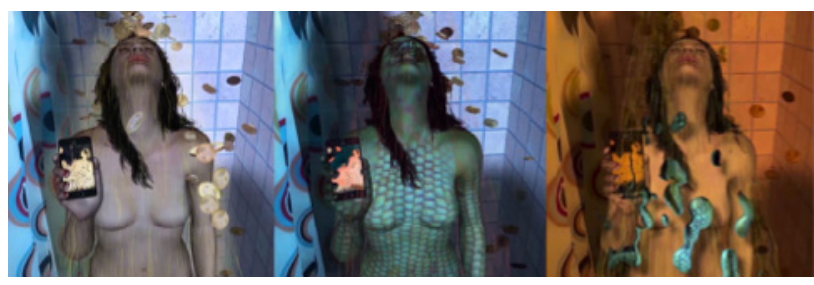

Figure 10: AR Blipp 46 (August 2016) of Selfie Drawing 44 "Golden Shower" (Sepember 2015)

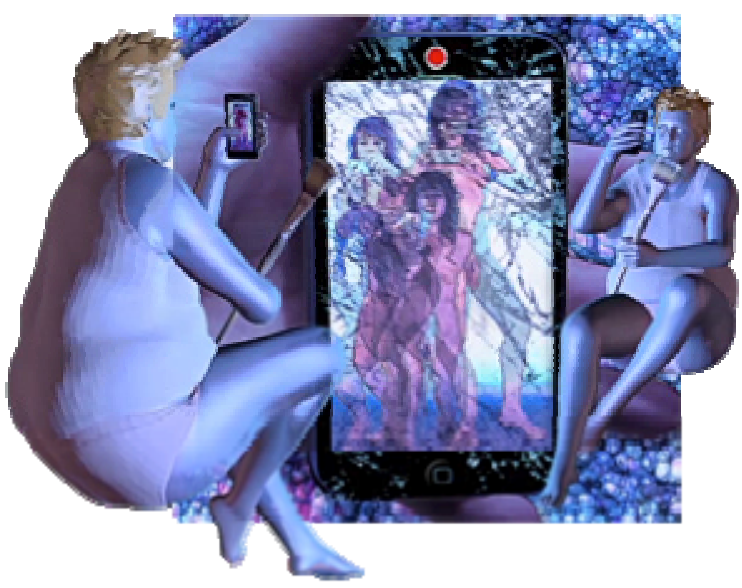

Figure 11: AR Blipp 41 (December 2016) of Selfie Drawing 30 "Demoiselles" (May 2015)

\subsection{Season Two}
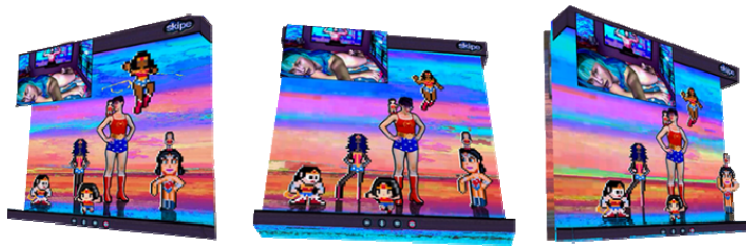

Figure 13: AR Blipp 44 (Aug 2016) of Selfie Drawing Selfie Drawing 31 "Peer-To-Peer" (May 2015)

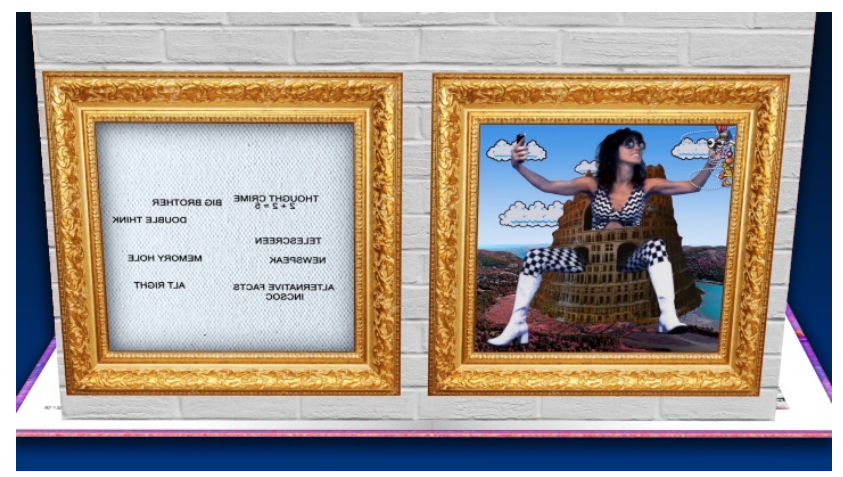

Figure 12: AR Blipp 47 (January 2017) of Selfie Drawing 41"Babel In Wonderland" (September 2015)

\subsection{Season Three}

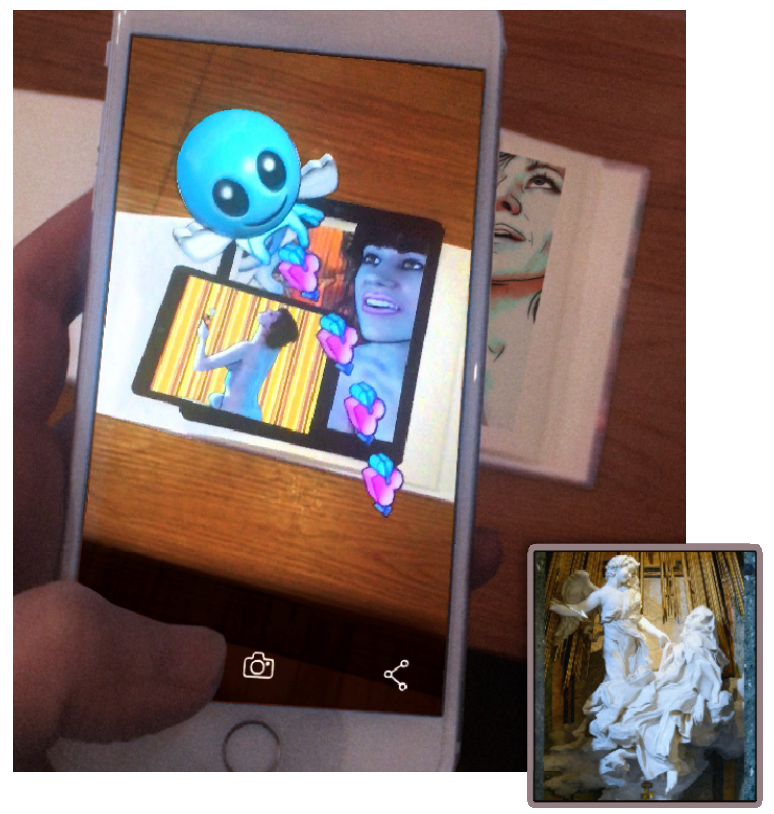

Figure 14: AR Blipp 42 (December 2016) of Selfie Drawing 50 "Teresa with Angel" (November 2015), inset: "Ecstasy of Saint Teresa" by Gian Lorenzo Bernini (Wikimedia Creative Commons License)

\subsection{Season Four}

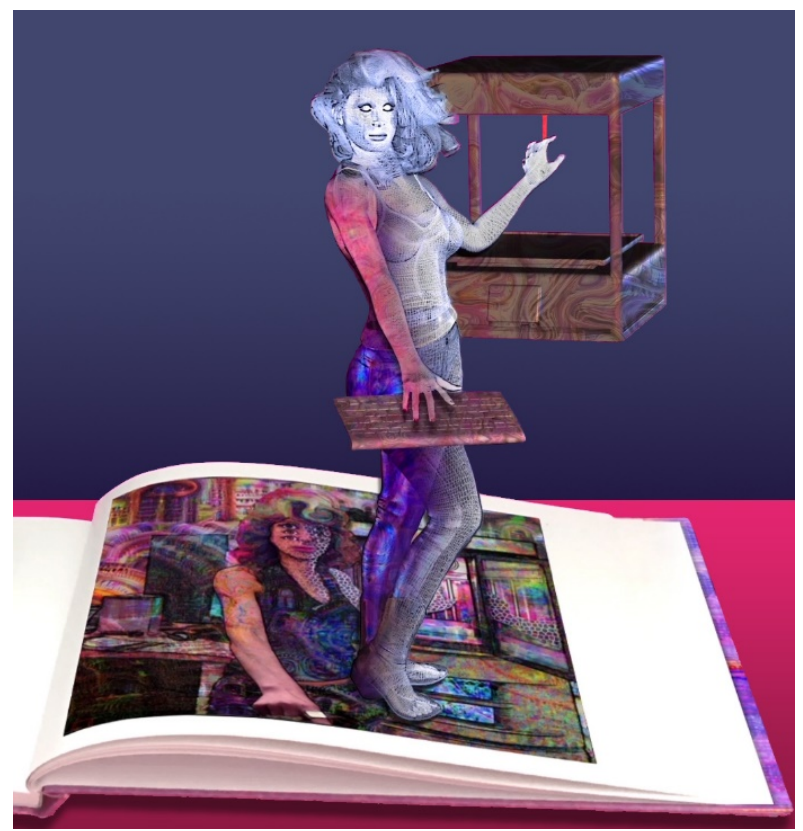

Figure 15: AR Blipp 51 (Feb 2017) of Selfie Drawing 49 "Post-Selfie" (October 2015)

\section{CLOSING}

There are challenges in trying to be seen and heard amidst the cacophony of networks, channels and platforms distributing content 24/7. More and more artists, like myself, are 
learning to use social networks and augmented realities as platforms for expanded, trans-disciplinary art action. It is important to harness electronic networks, and as critical, human networks, to be active creative participants in our future.

One of the most compelling - and sometimes daunting - aspects of digital narrative is how it can traverse electronic pathways and physical spaces in more adaptive ways than traditional mono mediums. For instance, in The Selfie Drawings project I began with digital drawings that I then translated into videos and interactive augmented reality works - from 2D to 4D. I have shared these works on social networks and in online exhibitions, as well as in physical galleries and media centres. Each iteration and locality provides a different emotional and cerebral context for the subject matter.

Through remixing the Canon and collaging it with current tropes and future speculations, I aim to embody the conflicts, humour, darkness and absurdity of human, earthly and cosmological conditions. It is my hope that this visual hybridity will resonate with people as a layered artefact of human cultural production over millennia.

I will end with an apposite quote by media theorist Janet Murray (1997) from her book Hamlet on the Holodeck.

"Not only is the computer the most capacious medium ever invented, but it also allows us to move around the narrative world, shifting from one perspective to another at our own initiative. Perhaps this ability to shift perspectives will lead to the technical innovation that will rival the Shakespearean soliloquy. ... All of these story patterns would be ways of enacting the contemporary human struggle to both affirm and transcend our own limited point of view."

\section{REFERENCES}

Carmichael, J. (2016) Did L. Frank Baum Predict Augmented Reality or Warn Us About Its
Power?https://www.inverse.com/article/18146-Ifrank-baum-the-master-key-augmented-realityfuturism (retrieved 15 January 2017).

Hollerer, T. and Schmalstieg, D (2016) Introduction to Augmented Reality, 8 March.

http://www.informit.com/articles/article.aspx?p=251 6729\&seqNum=2 (retrieved 18 January 2017).

Pollock D. (2017) 6 Awesome Facts You Need to Know About AR.

https://blippar.com/en/resources/blog/2017/03/08/6awesome-facts-you-need-know-about-ar/ (retrieved 20 March 2017).

Wright, R. Mobile Augmented Reality Art and the Politics of Re-assembly.

http://isea2015.org/proceeding/submissions/ISEA2 015 submission 341.pdf (retrieved 13 March 2017).

Pappenheimer, W. (2013) Critical Space. http://median.newmediacaucus.org/tracingnewmediafeminisms/critical-space/ (retrieved 18 March 2017).

Kruszelnickia, K. (2014) A brief history of the selfie. http://www.abc.net.au/science/articles/2014/08/12/4 065062.htm (retrieved 20 March 2017).

Syme, R (2015) Selfie: The revolutionary potential of you own face, in seven chapters, Nov 19. https://medium.com/matter/selfie-

fe945dcba6b0\#.7wtb03uya (retrieved 3 January 2016).

Santos, D. (2016) A Oneness With Everything, The Selfie Drawings. TRANSFER Gallery, NY, NY, pp. 6-9.

Rauschenberg, R. (1959) Quote.

https://www.goodreads.com/quotes/177412painting-relates-to-both-art-and-life-neither-can-be (retrieved 18 March 2017).

Chuk, N. (2016) Self-made: Constructing identity at the threshold between virtual and physical realms, Metaverse Creativity, 6, pp. 7-24.

Murray, J (1997) Hamlet on the Holodeck. MIT Press, Cambridge, MA, p. 283. 